\title{
SYSTEM SAFETY ANALYSIS
}

APPLICATION GUIDE

May 1993

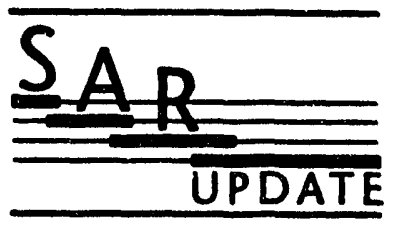

Issued by:

Central Safety Evaluation Team

MARTIN MARIETTA ENERGY SYSTEMS, INC.

Oak Ridge, Tennessee 
This repon has been reproduced directly from the best available copy.

Available to DOE and DOE contractors from the Office of Scientific and Technical Information, P.O. Bax 62, Oak Ridge, TN 37831; prices available from (615) 576-8401, FTS 626-8401.

Available to the public from the National Technical Information Service, U.S. Department of Commerce, 5285 Port Royal Rd., Springfield, VA 22161.

\section{DISCLAIMER}

This report was prepared as an account of work sponsored by an agency of the United States Government. Neither the United States Government nor any agency thereof, nor any of their employees, makes any warranty, express or implied, or assumes any legal liability or responsibility for the accuracy, completeness, or usefulness of any information, apparatus, product, or process disclosed, or represents that its use would not infringe privately owned rights. Reference herein to any specific commercial product, process, or service by trade name, trademark, manufacturer, or otherwise, does not necessarily constitute or imply its endorsement, recommendation, or favoring by the Urited States Government or any agency thereof. The views and opinions of authors expressed herein do not necessarily state or reflect those of the United States Government or any agency thereof. 
Safety Analysis Report Update Program

\section{SYSTEM SAFETY ANALYSIS \\ APPLICATION GUIDE}

May 1993

Issued by:

Central Safety Evaluation Team

MARTIN MARIETTA ENERGY SYSTEMS, INC.

Oak Ridge, Tennessee

Prepared for the U.S. Department of Energy under U.S. Government contract DE-ACD5-84OR21400 


\section{CONTENTS}

$\underline{\text { Page }}$

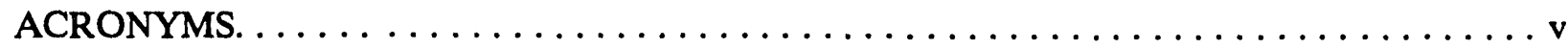

EXECUTTVE SUMMARY $\ldots \ldots \ldots \ldots \ldots \ldots \ldots \ldots \ldots \ldots \ldots \ldots \ldots$ vi

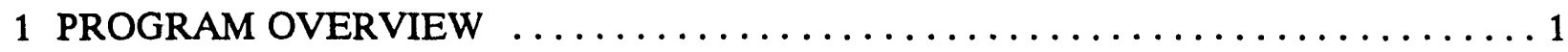

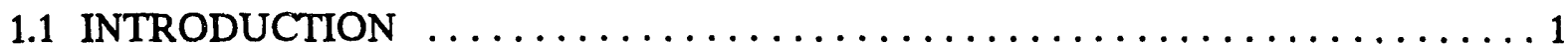

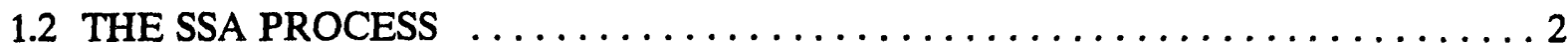

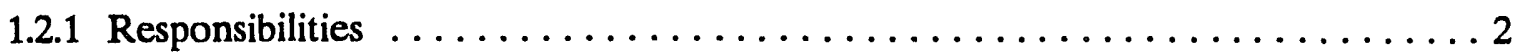

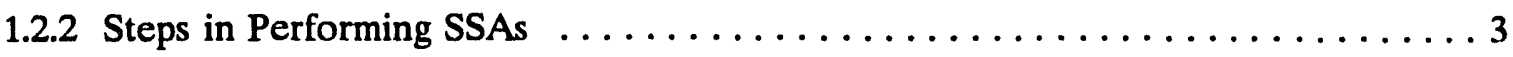

1.2.3 Relationship Between SSA and Other Safety Documentation $\ldots \ldots \ldots \ldots \ldots 4$

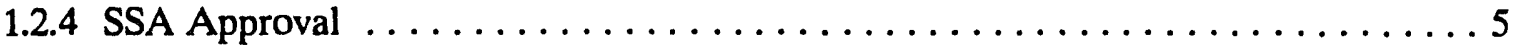

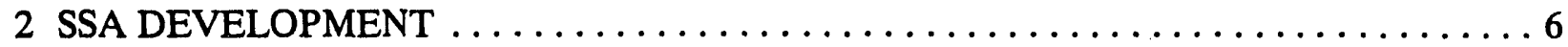

2.1 BASIC CONCEPTS AND CONSIDERATIONS $\ldots \ldots \ldots \ldots \ldots \ldots \ldots \ldots \ldots$

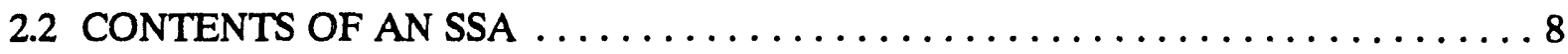

2.2.1 General Content Requirements $\ldots \ldots \ldots \ldots \ldots \ldots \ldots \ldots \ldots \ldots \ldots$

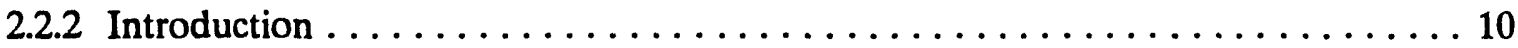

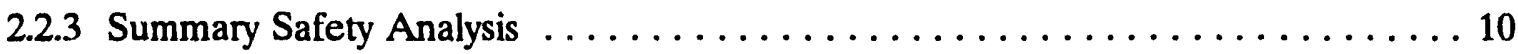

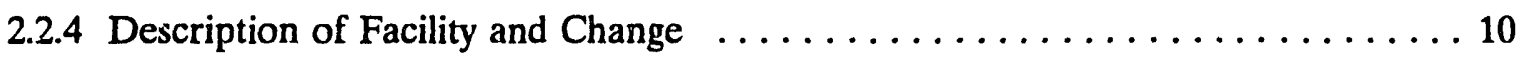

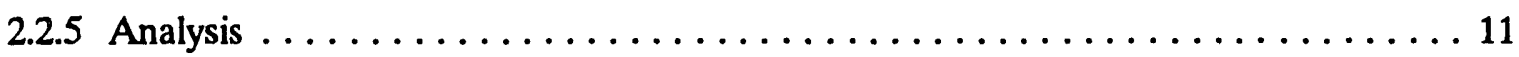

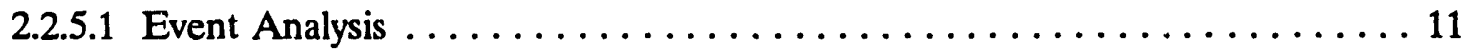

2.2.5.1.1 Methodology ........................ 11

2.2.5.1.2 Hazard Identification $\ldots \ldots \ldots \ldots \ldots \ldots \ldots \ldots \ldots \ldots \ldots \ldots \ldots \ldots \ldots \ldots$

2.2.5.1.3 Scenario Development . . . . . . . . . . . . . . . 12

2.2.5.1.4 Quantification of Consequences \& Frequencies ............ 13

2.2.5.1.5 Hazard Classification . . . . . . . . . . . . . . . . 14

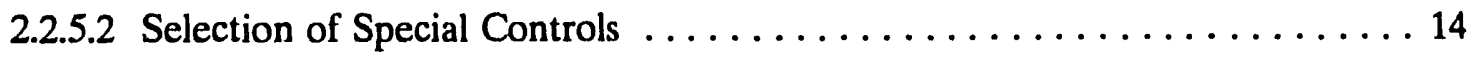

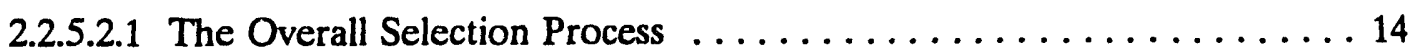

2.2.5.2.2 Significant Consequences and Importance to Safety . . . . . . . 14

2.2.5.2.3 Threshold Consequence Criteria $\ldots \ldots \ldots \ldots \ldots \ldots \ldots \ldots \ldots \ldots \ldots$

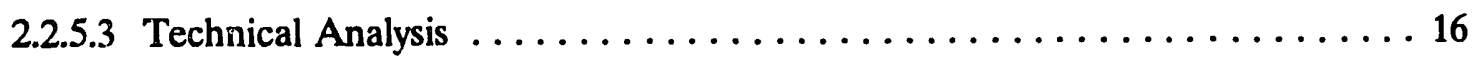




\section{CONTENTS (continued)}

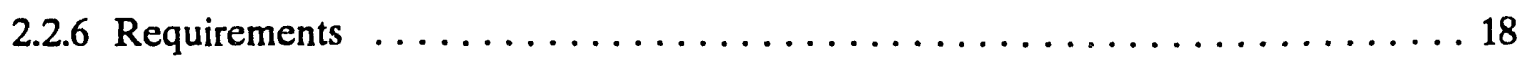

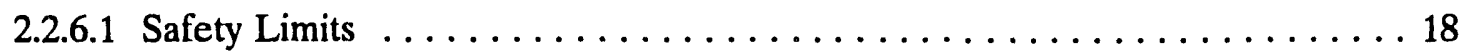

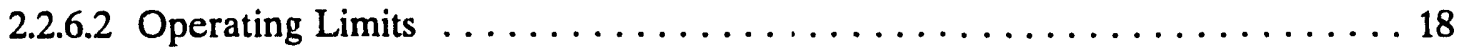

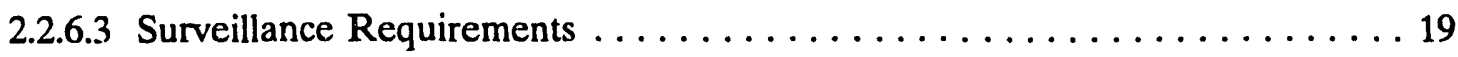

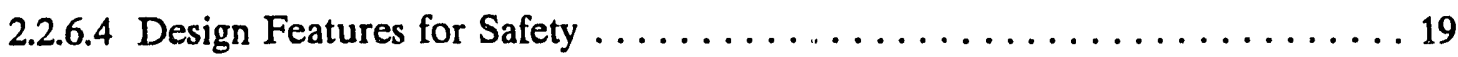

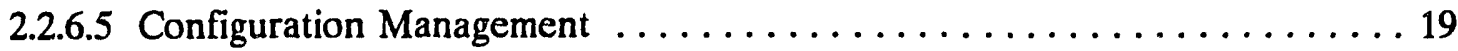

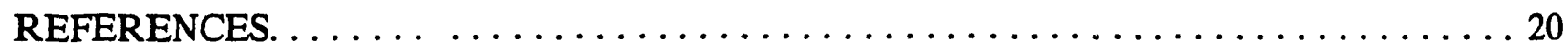

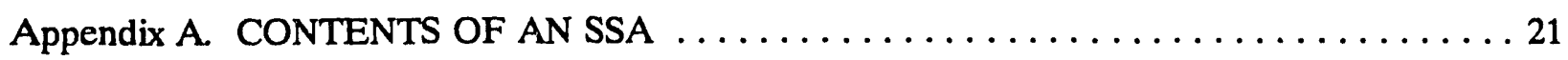




\section{ACRONYMS}

ALARA As Low as Reasonably Achievable

CFR Code of Federal Regulations

CSET Central Safety Evaluation Team

DFS Design Feature for Safety

DOE Department of Energy

ESS Energy Systems Standard

FSAR Final Safety Analysis Report

FSE Facility Safety Evaluation

GDP Gaseous Diffusion Plant

HAZOP Hazard and Operability Study

IFSM Installation Facility Safety Manager

LCO Limiting Conditions for Operation

LCS Limiting Control Settings

OSHA Occupational Safety and Health Administration

OSR Operational Safety Requirement

SA Safety Assessment

SAR Safety Analysis Report

SARUP Safety Analysis Report Update Program

SCI Safety Class Item

SL Safety Limit

SS Safety Study

SSA System Safety Analysis

TDLM Top Down Logic Model

TSR Technical Safety Requirement

USQ Unreviewed Safety Question

USQD Unreviewed Safety Question Determination 
............. 


\section{EXECUTTVE SUMMARY}

Martin Marietta Energy Systems, Inc., (Energy Systems) is committed to performing and documenting safety analyses for facilities it manages for the Department of Energy (DOE). Safety analyses are performed to identify hazards and potential accidents; to analyze the adequacy of measures taken to eliminate, control, or mitigate hazards; and to evaluate potential accidents and determine associated risks. Safety Analysis Reports (SARs) are prepared to document the safety analysis to ensure facilities can be operated safely and in accordance with regulations. SARs include Technical Safety Requirements (TSRs), which are specific technical and administrative requirements that prescribe limits and controls to ensure safe operation of DOE facilities. These documented descriptions and analyses contribute to the authorization basis for facility operation.

To meet changing mission goals, it is sometimes necessary to perform physical modifications and additions to facilities, to change procedures, or to perform tests and experiments at DOE facilities. Energy Systems' continuing commitment to safety requires a thorough evaluation of the impacts of these changes upon facility safety and the authorization basis.

Energy Systems has established a process to perform Unreviewed Safety Question Determinations (USQDs) for planned changes and as-found conditions that are not described and analyzed in existing safety analyses. The process evaluates changes and as-found conditions to determine whether revisions to the authorization basis must be reviewed and approved by DOE. There is an Unreviewed Safety Question (USQ) if a change introduces conditions not bounded by the facility authorization basis. When it is necessary to request DOE approval to revise the authorization basis, preparation of a System Safety Analysis (SSA) is recommended. An SSA provides information to assist DOE in reviewing and approving revisions to the authorization basis as a result of a change to a facility. Information from the SSA is used to prepare changes to the SAR and TSRs for a facility. When approved by DOE, the updated SAR and TSRs reflect the change to the facility and become part of the authorization basis for the facility.

This application guide describes the process of preparing an SSA and the desired contents of an SSA. Guidance is provided on how to identify items and practices which are important to safety; how to determine the credibility and significance of consequences of proposed accident scenarios; how to evaluate accident prevention and mitigation features of the planned change; and how to establish special requirements to ensure that a change can be implemented with adequate safety. 


\section{PROGRAM OVERVIEW}

\subsection{INTRODUCTION}

Energy Systems has established a Safety Analysis and Review System which is described in Standard ESS-FS-201 (ref. 1). According to the standard, this is a "... program that furnishes a basis for striving to excel in protecting the health and safety of the public, the workforce, property, and the environment from the hazards of Energy Systems operations..." This application guide describes activities associated with preparation of an SSA, which is part of the effort to protect the health and safety of the public and the workforce. These activities are coordinated with other activities to provide environmental protection (see Standard ESS-EP-101, ref. 2) and protection of government property through excellence in operations (see Standard ESS-OP-1, ref. 3).

DOE Order 5480.21 (ref. 4) requires that a safety evaluation be performed to determine whether a USQ is involved in a change at a DOE facility. Changes of interest include as-found conditions, proposed modifications to the physical facility or procedures as described in the existing safety analyses, or planned tests or experiments not described in existing safety analyses. This order requires that the evaluation determine if the change or as-found condition could result in a USQ, and that prior to implementation of planned actions DOE approval be obtained if the planned actions involve a USQ or a new or revised TSR. Energy Systems retains usage of Operational Safety Requirements (OSRs) as terminology for special requirements similar to TSRs for facilities through Phase IA of the Safety Analysis Report Update Program (SARUP). In this document, discussions of TSRs also apply to OSRs.

Energy Systems has developed a process for USQD, and it is described in ES/CSET-9 (ref. 5). The primary purpose of the USQD is to determine if a change (facility or procedure modification, test or experiment) can be made without review and approval by DOE. The USQD accomplishes this by determining whether the change could result in the facility being outside its authorization basis. If the authorization basis doesn't bound conditions which could result from the change, the change involves a USQ.

If a planned change involves a USQ or a new or revised TSR, it may be necessary to submit to DOE for review and approval proposed revisions to the authorization basis or new or revised TSRs. Previously, DOE has delegated to Energy Systems the authority to review and implement selected changes that could involve a USQ based on the hazard classification. Before preparing an SSA, the analyst should consult the Installation Facility Safety Manager (IFSM) to determine current approval requirements and the need for an SSA. When it is necessary to request DOE approval to revise the authorization basis or add, revise, or delete TSRs, preparation of an SSA is recommended. When results of the USQD indicate that DOE approval isn't required, the change may be implemented and any revisions to the SAR are incorporated during the annual SAR update process.

An SSA is a document which provides a description and analysis of a change or as-found cordition to assist DOE in reviewing and approving changes to the authorization basis, including TSRs. The SSA provides hazard identification, event analysis, and the technical basis for ensuring that risks associated with the change can be managed in an acceptable manner. The SSA demonstrates that the change includes provision for prevention and mitigation of postulated accident scenarios. The scope of the SSA should address only the safety related aspects of a change. In this 
regard, an SSA is unlike a full scale SAR since much of the site-specific description and general description of programs to ensure safety are either already in existence (post-SARUP) or are being prepared (during SARUP). The SSA examines a planned change to an existing facility to identify structures, systems, components, or practices where there could be accident scenarios with potential for significant risk of harm to the public or on-site workers. The identified items and practices are analyzed in the SSA to understand the credibility and consequences of postulated accident scenarios; to determine the importance to safety of such items and practices; and to assign limits, controls, and surveillance requirements commensurate with their importance.

This application guide is intended to explain how to identify items and practices which are important to safety; how to determine the credibility of accident scenarios; how to determine significant consequences of accident scenarios; how to evaluate accident prevention and mitigation features associated with a planned change; and how to establish special requirements to ensure safe implementation of a change. In general, accidents postulated in SSAs involve operation of facilities and performance of activities which pose significant nuclear, chemical, biological, or unusual highenergy hazards. Routine, minor hazards should be included in the scope of an SSA if these hazards can act as initiators, increase the consequences, or compromise mitigation of accidents involving significant nuclear, chemical, biological or high-energy hazards.

Energy Systems is currently engaged in the Safety Analysis Report Update Program for DOE installations at Oak Ridge (ES/CSET-1/R2, ref. 6) and Safety Analysis Report Upgrades for the Gaseous Diffusion Plants (GDPs) at Portsmouth, Ohio and Paducah, Kentucky. The purpose of these programs is to update and upgrade SARs to meet current DOE requirements. These activities are based on current facility configurations and practices and, depending on complexity and initial hazard classification of the facility, will take a few years to complete. Since missions of the facilities at these DOE installations are expected to change during SARUP and SAR Upgrade for GDPs, it will be necessary to make additions and changes to an authorization basis which may consist of interim documents. The purpose of an SSA is the same during SARUP and SAR Upgrade for GDPs and after completion of these programs. The SSA provides the technical basis for revisions or additions to the authorization basis by analysis of safety related aspects of changes and as-found conditions.

\subsection{THE SSA PROCESS}

\subsubsection{Responsibilities}

The IFSM at each installation coordinates and oversees implementation of the Energy Systems Safety Analysis and Review System, which is described in Standard ESS-FS-201 (ref. 1). The process of performing System Safety Analysis is part of the Energy Systems Safety Analysis and Review System. Each IFSM directs activities related to SSAs at their respective installations.

Line management at each installation has the responsibility (1) to create and maintain current facility-specific safety analysis documents (including SSAs as needed) for hazardous operations, (2) tc obtain authorization for operations at the installation in accordance with approved TSRs, (3) to provide for independent review of safety documents, and (4) to implement a process for USQDs for changes. Line management is responsible for the safe operation of hazardous facilities, subject to the advice of key safety analysis personnel and in accordance with the authorization basis. In 
conjunction with these broad responsibilities, line management works closely with the IFSM and participating support organizations in performing a System Safety Analysis.

System Safety Engineering provides safety analysis support services to line management as requested. This involves development of methods, providing training, development of expertise, performing evaluations and analyses, and providing other supporting activities to satisfy site-specific requirements related to safety analysis and review. Performance of SSA activities is part of this assigned mission.

\subsubsection{Steps in Performing SSAs}

During the early stages of SSA development it is important for an analyst to understand the scope and purpose of the change, to become familiar with those portions of existing authorization bases which could be impacted by the change, and to review previous safety analysis and evaluations to avoid repeating work already completed. There should be general agreer.ent among Operations, Installation Facility Safety, and the safety analyst on aspects of the change which require attention because of the potential to impact the authorization basis. At this point an analyst may prepare a brief plan to identify the tasks required to prepare an adequate SSA.

The major sequential steps for performing a System Safety Analysis are as follows:

1. Determine the scope and purpose of the change. This may be accomplished by a meeting of operations, installation safety staff, designers, and safe $y$ analysts. A team visit to the facility impacted by the change is recommended.

2. Review the existing authorization basis. Begin to focus attention on the portions of the authorization basis which are impacted by the planned change.

3. Review any previous safety evaluations concerning the planned change. This may include completed as well as incomplete Safety Reviews and USQDs. Look for at least the following information which may be useful in performing the SSA.

a. Reasons for revisions or additions to the authorization basis.

b. Extent of the impact on the authorization basis.

c. Existing analysis, logic, assumptions, or references which may be used is source information in performing the SSA.

4. Review safety evaluations associated with previous changes to the plant features, interfacing features, or procedures affected by the current change to ensure that none of the previous safety evaluations are invalidated.

5. Prepare a brief plan of minimum activities needed to prepare the SSA.

6. Implement the planned approach performing only required activities needed iv address safety related aspects of the change. Activities collectively referred to as "event analysis" in this document may already be recorded in existing, approved safety documents. Such work should be summarized and referenced in the SSA. 
7. Identify items (structures, systems, and components) and practices (operating and maintenance procedures) wr: $h$ are important to safety, complete necessary technical analysis, identify new or changed Safety Class Items (SCIs) and TSRs, and prepare the SSA documentation in accordance with Section 2 of this document.

8. Issue a draft SSA document for comment and be prepared to support contents of the document with analysis and references. Resolve review comments and issue the SSA document for Energy Systems approval.

9. Assist the IFSM in obtaining DOE approval of proposed revisions to the authorization basis as requested.

\subsubsection{Relationship between SSA and Other Safety Documentation}

When major construction activities are planned at a DOE installation, it is important to determine whether or not it creates a new facility or is a change to an existing facility. The SSA is used to provide a basis for DOE review and approval of changes to the authorization basis or TSRs for an existing facility. Preparation of an SSA is inappropriate to establish the authorization basis or TSRs for a new facility. When a new facility is planned for a DOE installation, a Safety Assessment (SA) is performed early in the design process in accordance with ES/CSET-13 irei. 7). If the hazard classification is high or moderate, a Final Safety Analysis Report (FSAK) is needed. If the hazard classification is low, a Safety Study (SS) is needed. Guidance on preparation of SARs is contained in ES/CSET-12 (ref. 8) and the preparation of a SS is explained in ES/CSET-18 (ref. 9).

When it is necessary to make changes to a facility which has safety documents being updated during SARUP, a USQD is prepared. An SSA is prepared for changes which require DOE approval because of a USQ or a change to the TSRs (or OSRs). The SSA may serve as a part of the authorization basis until information from the SSA is either incorporated into a Facility Safety Evaluation (FSE) during Phase II or included in the completed SAR in Phase III of SARUP (see CSET-10, ref. 10 and ES/CSET-12, ref. 8).

Generally, the USQD is the initial safety evaluation prepared in conjunction with a planned change to an existing facility. The USQD is performed in accordance with ES/CSET-9 (ref. 5) and DOE Order 5480.21 (ref. 4). There is a USQ whenever the change increases the probability or consequence of an accident or malfunction of equipment important to safety, the change creates an accident or malfunction of a different type than any already described in the authorization basis, or the change reduces the margin of safety. In cases where there is no USQ and no impact on TSRs, it is not necessary to prepare an SSA. In this case, the USQD provides documentation of the change, and it may be implemented without review and approval by DOE since the facility remains within its authorization basis. The facility safety documentation would be revised to include changes made using the USQD process in the normal periodic update as described in ES/CSET-9 (ref. 5).

DOE approval is required when changes involve new, revised, or deletion of TSRs, or when DOE hasn't delegated to Energy Systems the authority to implement changes that involve USQs based on hazard classification. When it is necessary to obtain DOE approval, an SSA is prepared to provide technical basis for the proposed changes to the SAR and TSRs. When the USQD contains quantitative analysis, it is not necessary to repeat the analysis in the SSA. The SSA should 
surnmarize and reference completed, approved safety docunients in the interest of economy. The rigor of the SSA should be equivalent to the existing authorization basis, unless the change increases the hazard level. In this case the rigor of the SSA should be commensurate with the higher hazard level. For a change to a facility which has a completed SAR and TSRs, the SSA in not intended to be part of the authorization basis. Information from the SSA is used to prepare proposed page changes which, upon DOE approval, would be incorporated into the SAR and TSRs. In this manner the authorization basis is maintained current relative to ongoing changes.

There may be changes which do not involve a USQ, but require acditional or revised TSRs. For example, modifications to a facility in the Y-12 Plant were evaluated by the USQD process in August 1992. The USQD determined that the modified facility would be within the envelop of existing, approved safety analysis and there was no USQ. However, additional OSRs were established, with DOE approval based on existing analysis. In this case, no SSA was needed because the existing safety analysis provided sufficient basis for the additional OSRs.

Changes may involve no USQ and result in elimination of the need for existing TSRs. For example, suppose the change is to remove an existing subsystem which has a TSR for a component that is important to safety. Further suppose the safety related function of the subsystem is no longer required. In this case there is no USQ, but requirements on the subsystem should be deleted from the TSRs, and the description of this subsystem should be deleted from the SAR. Since DOE approval is required to delete TSRs (and OSRs during SARUP), preparation of an SSA is recommended to provide DOE with necessary background information to facilitate review and approval.

\subsection{SSA Approval}

Standard ESS-FS-201 (ref. 1) indicates that the IFSM establishes installation policy and prepares installation-specific implementation procedures for the Safety Analysis and Review System. Therefore, approval of an SSA may vary among installations. Standard ESS-FS-201 describes the significance of approval by various levels of management, but specific approval requirements are established at each installation.

According to Standard ESS-FS-201, approval by the Installation Manager denotes acceptance of risk management responsibility and commitment to enforce limitations identified in the SSA and proposed revisions to the authorization basis. The IFSM recommends approval by the Installation Manager based on the conclusion that the SSA provides a technical basis for the approach taken to control hazards. Technical correctness, completeness, and adequate support for conclusions in the SSA are provided by requirements for approval by the Independent Review Chairman, System Safety Engineering, and the appropriate operations organization. When a change necessitates revisions to the authorization basis, the SSA (approved in accordance with installation procedures) should accompany the proposed revisions submitted to DOE for approval. 


\section{SSA DEVELOPMENT}

\subsection{BASIC CONCEPTS AND CONSIDERATIONS}

The primary purpose of an SSA is to provide information to assist DOE in reviewing and approving revisions to the authorization basis as a result of changes to a facility. During SARUP, the SSA may serve as an interim part of the authorization basis until information from the SSA is incorporated into an FSE or SAR in Phases II and III, respectively. For facilities having current SARs and TSRs, information from the SSA is used to prepare change pages to the SARs and TSRs which, when approved by DOE, update the authorization basis to reflect the change to the facility. An SSA serves its basic purpose by providing the following information:

1. Description of the change to the facility and its operation.

2. Summary of why the change requires revision of the authorization basis.

3. Brief statement as to what it is about the change that constitutes a USQ, if the change involves a USQ.

4. Explanation of any change to the facility hazard classification as a result of the change. This is determined by event analysis which is either included in the SSA or is summarized in the SSA with reference to existing documents.

5. List of items and practices which are important to safety. These are structures, systems, components, or operational practices whose failure could result in significant risk of harm to the public or on-site workers. In general, these items and practices function to prevent or mitigate accidents.

6. Special requirements which Energy Systems is committed to satisfy and which are required to ensure acceptable management of hazards associated with the change.

7. Demonstration of the a septability of special requirements using technical analysis. This includes a comparison of functional safety requirements for items important to safety with the performance capability and capacity of these items. This should include a quantitative determination of safety margin, if feasible.

8. Identification of any items or documents associated with the change which have previously been under configuration management or any new or modified items or documents which must be under configuration management. The purpose of this is to ensure that the facility's physical and functional characteristics are maintained in conformance with the safety analysis documentation.

An SSA contains analysis similar to that required in a SAR as described in ES/CSET-12 (ref. 8). However, the scope of an SSA is limited to the safety related aspects of a change. Since many of the generic topics contained in a full scope SAR either are in place or are being prepared, these should not be repeated in an SSA. Examples of topics which may be excluded from SSAs include site characteristics; organization; existing health and safety criteria; and installation-wide 
programs such as radioactive and waste management, criticality prevention, radiation protection, training, conduct of operations, quality assurance and emergency preparedness. The hazard level of the facility including the change is compared with the hazard level of the existing facility, and the higher level is used to determine the rigor of the SSA. The level of the analytical treatment in an SSA should be commensurate with the higher hazard level. For low hazard classification, the rigor of the SSA should be comparable to that of an SS; see ES/CSET-18 (ref. 9). If the hazard classification is moderate or high, the rigor of the SSA should be comparable to that of an FSAR. This is in accordance with the concept of graded approach. This concept allows application of levels of sophistication of analysis and thoroughness of documentation which are proportional to the magnitude of the hazards involved; see DOE Order 5480.23 (ref. 11).

In developing an SSA it is important to recognize the differences between event analysis and technical analysis. In this document, event analysis refers to any of the hazard analysis techniques which result in hazards identification, accident scenarios, consequences and frequencies of scenarios, and hazard classification. In part, technical analysis is intended to examine the capability and capacity of items which are relied upon to prevent or mitigate postulated accidents to show they can be expected to perform as required under normal operating conditions and to estimate the performance of such items under the challenges of operational upsets.

Results of previously completed event analyses may be included in the SSA by identifying and briefly summarizing reference documents. If results are not available from other sources, event analyses should be included in the SSA. Recommended phases of event a alysis, along with references which provide guidance for performing the analysis, include the following topics. "Hazard Identification" described in ES/CSET-2/R1 (ref. 12) results in identification of hazards, selection of initiating events, and development of quantitative descriptions of consequences. "Scenario Development" uses logic modeling in accordance with ES/CSET-3/R1 (ref. 13) to develop top-down logic models (fault trees) and event trees. Top-down logic models reveal items and practices which are important in preventing unwanted events. Event trees show the events following an accident and address mitigation of the event through detection, confinement, ventilation, and recovery as appropriate. "Quantification of Consequences and Frequencies" is based on hazard analysis and CSET-10 (ref. 10) which shows how to determine frequencies by quantifying fault trees and event trees. "Hazard Classification" is determined by comparing estimated consequences at various locations with established criteria to indicate potential severity of postulated accident scenarios. It is noted that alternative methods of event analysis may be used. Regardless of methods used, as a minimum, results should include identification of hazards, hazard classification, and a determination of the credibility of postulated accident scenarios.

An SSA also provides technical analyses of the capability and capacity of items and practices which are important to safety so that review and approval of changes and as-found conditions may be accomplished with acceptable assurance that functional safety requirements are satisfied. As described above, event analysis makes it possible to identify the items and practices which are important to safety. Attention is then directed to comparing capabilities and capacities of these items with functional safety requirements under various operating and upset conditions. 


\subsubsection{General Content Requirements}

Historically, a broad spectrum of changes have occurred at DOE installations, and the potential for future changes to impact safety is expected to range from negligible to highly significant. Use of a graded approach in the evaluation of these impacts is recommended, with greater effort directed toward understanding and analyzing the more severe hazards; see DOE Order 5480.23 (ref. 11). Therefore, it is not possible to specify the exact level of detail to include in an SSA. The organization and structure of the SSA document are shown in Appendix A; and later sections describe the desired topics in each part. However, the following general guidelines are offered for the entire document:

1. The level of detail should be commensurate with the complexity of the change, the severity of the hazards involved, and the rigor expected for the higher hazard classification determined by comparing the changed facility and the existing facility.

2. The SSA should concentrate on those aspects of the change which have potential to impact the authorization basis and are found by analysis to be important to safety. Other topics which may reasonably be expected to be important to safety, but which can be shown in the analysis to be of lesser importance, should also be explained sufficiently to show they have been considered and are found not to be significant. The SSA should avoid describing and analyzing the parts of the existing facility not involved with safety of the change.

3. Sufficient descriptions should be provided for methods, assumptions, models, references, technical data, and scientific principles to enable an independent reviewer to follow the logic and judge the credibility of the results.

4. In cases where results of previously completed (and approved) safety documents are used, some of the sections are optional. For example, if event analysis appears in an approved safety document, the results may be referenced and summarized in the SSA.

The scope of an SSA is limited to the safety related aspects of a change, and the content should be the minimum necessary to analyze and review the essential aspects of the change with emphasis on providing support for changes or additions to the authorization basis. Therefore, the SSA is organized in a simple five chapter format. A summary of the content of the chapters is shown in Table 1 with reference to applicable sections of DOE/OR-901 (ref. 14) for additional guidance. This updates information in Table 2.8-1 of ES/CSET-12 (ref. 8) to reflect the current concept of SSA contents. 
Table 1. System Safety Analysis Content

\begin{tabular}{|c|l|l|l|}
\hline Chapter & Title & Contents & $\begin{array}{l}\text { DOE/OR-901 } \\
\text { Sections }\end{array}$ \\
\hline 1 & INTRODUCTION & $\begin{array}{l}\text { Provide a brief description of the } \\
\text { change, why the change is being } \\
\text { made, why there is a USQ, and why } \\
\text { there is a need to change the } \\
\text { authorization basis }\end{array}$ & $1.1,1.2,1.3$ \\
\hline 2 & $\begin{array}{l}\text { SUMMARY } \\
\text { SAFETY } \\
\text { ANALYSIS }\end{array}$ & $\begin{array}{l}\text { Summarize the results of the analysis } \\
\text { and the special requirements }\end{array}$ & $2.1-2.4$ \\
\hline 3 & $\begin{array}{l}\text { DESCRIPTION } \\
\text { OF FACILITY }\end{array}$ & $\begin{array}{l}\text { Describe the safety related aspects of } \\
\text { the facility and the proposed change }\end{array}$ & $\begin{array}{l}4.4,4.5,4.7,5.1, \\
5.3,5, \\
6.1\end{array}$ \\
\hline 4 & ANALYSIS & $\begin{array}{l}\text { Provide event analysis and technical } \\
\text { analysis; provide the technical basis } \\
\text { for selection of special requirements }\end{array}$ & $\begin{array}{l}10.1-1.1 \\
11.1\end{array}$ \\
\hline 5 & REQUIREMENTS & $\begin{array}{l}\text { Provide special requirements } \\
\text { associated with the change; provide } \\
\text { conditions, limitations and controls } \\
\text { needed to ensure safe operation of } \\
\text { the facility after the change }\end{array}$ & $13.1,13.2$ \\
\hline
\end{tabular}




\section{2 .2 Introduction}

Section 1 of the SSA should provide a brief description of why the change is being made and why an SSA is prepared. A brief explanation should be given of the reason the change involves a USQ, or addition or revision of TSRs. Existing authorization basis documents impacted by the change should be identified. The "Introduction" should identify the facility being modified; its location and primary mission; and the organization responsible for safety of operation and use of the facility after the change is incorporated. The bounds and interfaces between the change analyzed in the SSA and the adjacent facility should be described. The perspective of this overview should indicate whether the change introduces a new process not previously performed at the facility or if the change involves the same process with greater capacity, improved efficiency, higher quality product, or some other desirable result. The "Introduction" is the place to put the change in perspective relative to the total facility purpose and mission without details which appear in later sections of the SSA.

\subsubsection{Summary Safety Analysis}

Section 2 of the SSA should summarize the risks associated with the change. Significant hazards should be summarized here. The consequences and frequencies should be stated for credible scenarios. Those items and practices which the analysis finds important to safety should be summarized, including a brief description of why each is important. This section must indicate whether the hazard level of the facility is changed and indicate whether there are new or modified TSRs. The type requirements (Safety Limits or Limiting Conditions of Operation) established in Section 5 of the SSA should be summarized.

\subsection{Description of Facility and Change}

The purpose of Section 3 of the SSA is to provide a brief description of the facility and a complete description of safety related aspects of the change. The facility description should include the location; principal use of the facility; the process being modified; hazards associated with the change; potential hazards for which the change could be an initiator; description of safety functions; and safety features of facility structures, layout, and services. The facility description may contain a site (installation) map and a plan view of the local area or building interior. In the interest of brevity, judgement is needed to select those features of the facility that are to be described. For example, consider a change which introduces a credible scenario for exposure of the on-site population or offsite public to harmful levels of an airborne substance (either toxic or radioactive). In this case, the facility description may include the ventilation system, the volume of the space where the accidental release could occur, the confinement features of the facility, and any monitoring system which could alert persons that a release has occurred. To keep this part brief, the preparer should aivid a comprehensive description of the building structures and services if they have no bearing on safety related aspects of the change. For example, do not describe the building electrical power system, compressed gas distribution system, steam, condensate, or the water system if they have no influence on safety of the change. 
Description of changes to a process should include why the change is necessary and how the process would be operated differently after the change is implemented. This section should be written after the analysis is complete because that activity wil! determine the items and practices associated with the change which are important to safety. Emphasize the aspects of the change which affect the following areas: additions or modifications to major equipment, system configuration, inventory of hazardous materials, stored (potential) energy, primary process containment boundary (pipes, pumps, and vessels), instrumentation and control system, and operating and maintenance procedures. The description of the process changes should address practices which are safety related during initial start-up testing, charging the system with hazardous material, normal operations, shutdown and maintenance operations, routine testing and inspection operations, anticipated transients, accidents, unloading hazardous materials, clean-out, and any special operational modes.

\subsubsection{Analysis}

\subsubsection{Event Analysis}

The purpose of event analysis (Section 4.1 of an SSA) is hazard identification, development of accident scenarios, determination of consequences and frequencies of scenarios for a change, and hazard classification of the changed facility. This analysis is primarily concerned with those aspects of the change which could expose the public or members of the on-site population to significant hazards. Event analysis consists of a combination of qualitative and qua. . itative methods. The beginning steps of event analysis involve qualitative considerations in identifying the hazardous substances and conditions and postulating initiating events and accident scenarios which could lead to undesirable consequences. The later siages of event analysis utilize quantitative methods to estimate the frequency of occurrence of selected scenarios and to calculate consequences which could result from postulated accident scenarios. If all or portions of event analysis already exist in approved safety documents, this work should not be repeated in the SSA. Instead, the SSA should provide a brief summary of each appropriate reference.

\subsubsection{Methodology}

Section 4.1.1 of an SSA (see Appendix A) should summarize the methods, assumptions, models, and principles used in event analysis. Liberal references may be made to guidance documents approved by the Central Safety Evaluation Team (CSET).

\subsubsection{Hazard Identification}

It is recommended the analyst use a Preliminary Hazards Identification Matrix form to list the hazardous substances and conditions (see ES/CSET-2/R1, ref. 12). Examples of sources of information useful in identifying hazards include site visits; discussions with design, operations and maintenance personnel; design documents; operation and maintenance literature provided by equipment manufacturers; and listings of hazardous materials such as those on Material Safety Data Sheets. Once hazards are identified, it is recommended that the analyst utilize Preliminary Hazards Analysis Worksheets to determine which are standard industrial hazards. Standard industrial hazards may be excluded from further analysis unless they serve as potential initiators, increase consequences 
or compromise mitigation of accidents involving significant hazards. ES/CSET-2/R1 (ref. 12) explains that standard industrial hazards are the type encountered in general industry that are adequately controlled by Occupational Safety and Health (OSHA) regulations such as 29 CFR 1910 (ref. 15). However, there is an important exception to this criter/a for excluding standard industrial hazards from analysis. Article 1910.119 was added to 29 CFR i 910 in the July 1,1992 revision requiring the process safety management of "highly hazardous chemicals." CSET recommends that highly hazardous materials not be excluded from further analysis if the inventory in a DOE facility could exceed the "threshold quantities" listed in Appendix A of article 1910.119, 29 CFR 1910.

Nonstandard industrial hazards should be developed further using Modified Hazard and Operability Study (HAZOP) Worksheets. This activity is a structured approach to systematically examine postulated deviations and initiating events which could cause the release of high-energy or hazardous materials. This activity should eliminate hazards for which there are no initiators or deviations which could result in hazardous conditions. The postulated deviations and initiating events which could result in loss of control of hazardous materials or energy form the basis for scenario development that is discussed in the next section. Detailed descriptions of how to perform the qualitative analyses just summarized are contained in Sections 2.1, 2.2, and 2.3 of ES/CSET-2/R1 (ref. 12).

Results of the activities described above for hazard identification should appear in Section 4.1.2 of an SSA (see Appendix A). Completed forms (such as Preliminary Hazards Identification Matrix, Preliminary Hazards Analysis Worksheets, and Modified HAZOP Worksheets) may be included in appendices to the SSA. Section 4.1.2 should identify those hazards which are standard industrial and the reasons no realistic initiating events are thought to exist for some hazards.

\subsubsection{Scenario Development}

Accidents-of-interest for changes are formed by grouping together those events having similar qualitative consequences as indicated by results of the hazard identification process. For example, if the change is to introduce into a facility a large storage vessel containing anhydrous hydrogen fluoride (HF), the accident-of-interest would be the release of HF which escapes its containment boundary and becomes airborne. The hazard associated with this accident is the toxicity experienced by persons who might inhale the HF. All initiating events and sequential paths of failures creating this risk would form the various scenarios by which this accident could occur. It is recommended that scenario development be accomplished by developing a fault tree or Top Down Legic Model (TDLM) for the scenarios which could produce the accident-of-interest. The TDLM includes events and conditions leading up to the accident, and preventors will be evident by examination of the TDLM. Post-accident events are shown in an event tree which addresses mitigation of the event through detection, confinement, ventilation, and recovery actions by equipment and operations or emergency response personnel. ES/CSET-3/R1 (ref. 13) provides detailed, step-by-step instructions for creating TDLMs and event trees.

Results of "Scenario Development" should be summarized in Section 4.1.3 (see Appendix A) of an SSA and TDLMs and event trees may be included in an appendix. The text of Section 4.1.3 should contain a description of postulated accident scenarios. 


\subsection{Quantification of Consequences and Frequencies}

The quantitative analysis normally involved in event analysis proceeds along two parallel paths: consequence determination and frequency determination. Each path is now explained, along with guidance on minimizing the analytical effort. For the initial quantification of consequences and frequencies, it is suggested that conservative, simplifying assumptions be made. This is intended to produce intentionally pessimistic predictions of risk at minimal cost. If these initial, conservative efforts show consequences are insignificant or so infrequent that they are incredible (typically less than $10^{-6}$ per year), then subsequent analysis may be unnecessary.

Initiators from the worksheets described previously become basic events in TDLMs for the accidents of interest. The series of conditions and failures which are traced through the TDLM from one or mor $u$ basic events (initiators) to the top event (accident of interest) is called a "cut set." Each cut set is a specific scenario leading to the accident of interest. Probability risk analysis software is available to determine the frequency (or probability) of each cut set and to combine all the cut sets to determine the overall frequency (or probability) of the accident of interest. A postulated event is considered credible if the frequency of occurrence is $10^{-6}$ per year or greater. A postulated event having a frequency of occurrence which is less that $10^{-6}$ per year is normally considered to be incredible and need not be analyzed, depending on the consequences, risk and confidence in the estimate of the frequency. For events which could have catastrophic consequences, additional analysis should be considered for frequencies of occurrence lower than $10^{-6}$ per year (DOE/OR-901, ref. 14).

For each credible accident scenario, it is necessary to determine the amount of material at risk, the amount which could be released, and the dispersion of the hazardous substances to which workers and the public could potentially be exposed. For scenarios involving similar hazards and release and dispersion mechanisms, those with potential to release the largest amounts of hazardous materials should be analyzed first. In this manner the analysis will concentrate effort on scenarios for each accident-of-interest posing the greatest threat to the health and safety of the public and onsite population. If hazard exposure estimates of the postulated most severe scenarios are acceptable, then it may be unnecessary to determine the consequences of the less severe scenarios. Judgement and caution are advised in eliminating scenarios from consequence analysis. It is noted that analysis of scenarios with less severe consequences may be necessary to identify SCIs so that limiting conditions, controls and surveillance are appropriately established. Consequence analysis should be performed to the level of rigor required in DOE/OR-901 (ref. 14) and DOE Order 6430.1A (ref. 16). CSET-10 (ref. 10) contains instructions on obtaining solutions to TDLMs and event trees.

Section 4.1.4 of the SSA (see Appendix A) should summarize quantitative results for consequences and frequencies of important accident scenarios. Detailed records of the analysis may be presented in an appendix of an SSA or reference may be made to "stand alone" calculations. Detailed analysis should address postulated accidents introduced by the proposed change and previously analyzed accidents affected by the change. Accident scenarios of greatest concern to safety should be determined by predicting consequences and estimating the frequency of occurrence of scenarios caused by initiating events including equipment failure, operating error, process excursions, and natural phenomena events (wind, flood, earthquake, or tornado). 


\subsection{Hazard Classification}

Accident scenarios having the most severe consequences determine the hazard classification of the changed facility. The hazard classification is high, moderate, low, or generally accepted depending on the location of persons affected by the hazards and the severity of estimated health effects. It is noted that the IFSM at Y-12 has divided the generally accepted hazard level into "minor" and "generally accepted" levels. Facilities with radiological or toxic material below the threshold for classification as low hazard facilities are to be classified as "minor" at $Y^{\prime}-12$ instead of being classified as generally accepted. Analysis should be performed to estimate radiation doses and concentrations of toxic materials at various distances from the source term. Human response to estimated levels of ionizing radiaiion and toxic materials may be determined as irreversible, reversible, or negligible by comparing estimated exposures with threshold values for these effects. Results of hazard classification should be summarized in Section 4.1.5 of the SSA (see Appendix A).

\subsubsection{Selection of Special Controls}

\subsection{The Overall Selection Process}

Once results of event analysis are available from Section 4.1 of the SSA (or appropriate references), it is possible to identify items and practices which are important to safety. This may be accomplished by examining fault trees (TDLMs) and event trees to determine the items and practices which are involved in postulated accident scenarios which are both credible and are estimated to produce consequences which could cause significant risk of harm to the public or on-site population. This section describes criteria for determining whether consequences are "significant," and the previous section defined credible scenarios typically as those with estimated frequency greater then $10^{-6}$ per year. Special requirements are established for those items and practices which are determined to be important to safety to ensure that safety functions will occur as required. The special requirements consist of limits, controls and surveillance activities that form the basis for Technical Safety Requirements (TSRs) required by DOE Order 5480.22 (ref. 17).

\subsection{Significant Consequences and Importance to Safety}

First, some of the qualitative terms used to describe safety related aspects of a change are clarified. DOE/OR-901, Appendix C, (ref. 14) indicates SCIs are those "... whose failures could adversely affect the safety and health of the public, facility personnel, site workers, or cause unacceptable impact to the environment." DOE Order 5480.23 (ref. 11) requires the performance of a hazard analysis to categorize processes, operations, or activities according to potential consequences of releases of radioactive or hazardous materials. Category 1 Hazards have potential for "significant" off-site consequences, and Category 2 Hazards have potential for "significant" on-site consequences. Category 3 Hazards show potential for only "significant" localized consequences. The next few paragraphs provide guidance for preparation of SSAs to assist in identification of items and practices which could "adversely" affect, cause "unacceptable" impact, or have "significant" consequences on the health and safety of persons on-site or off-site. 
One of the criteria contained in DOE Order 5480.21 (ref. 4) for determining if a change involves a USQ focuses on whether the change involves new equipment which is "important to safety" and if the change could cause a malfunction of existing equipment.which is "important to safety." The CSET recommends that for preparing SSAs, items which are "important to safety" as described in DOE Order 5480.21 be considered the same as "Safety Class Items" described in DOE/OR-901 (ref. 14). Since postulated accident scenarios leading to significant risk of harm can involve improper practices as well as failures of structures, systems, and components ("items"), CSET considers that there are practices which are equally as important to safety as these items.

\subsubsection{Threshold Consequence Criteria}

By examining fault trees and event trees and by comparing quantitative consequence results from event analysis with threshold consequence criteria, the postulated scenarios which contain Safety Class Items (SCIs) and practices equally as important to safety as SCIs can be identified. Items and practices should be designated SCIs, or practices equally as important to safety as SCIs, if they are involved in postulated accident scenarios which are considered credible and could have consequences exceeding threshold consequence criteria contained in ES/CSET-15 (ref. 18).

ES/CSET-15 provides the method of combining consequences and frequency of occurrence to select SCIs for postulated scenarios estimated to occur more frequently than $10^{-6}$ per year and having estimated consequences above threshold levels. In this document CSET extends this concept (described in detail in ES/CSET-15) to selection of practices which are equally as important to safety as SCIs. The concept of applying threshold criteria for selection of SCIs and practices equally as important to safety as SCIs is not intended to detract from the principle of "as low as reasonably achievable" (ALARA).

Selection of SCIs and practices equally as important to safety as SCIs concentrates on scenarios involving credible breaches of containment boundaries and confinement features with potential to release radioactive or other hazardous substances to the public and on-site workers. Caution is needed to avoid overlooking other hazards which could be equally important. DOE/OR901 (ref. 14) recommends consideration of unusually severe or extensive industrial-type accidents which might not involve release of radioactive or toxic material, but could endanger the public or onsite persons. An example of this type accident is a very large release of energy such as an explosion. Items and practices whose failure could result in risk of significant consequences involving such scenarios should be considered candidates for status as SCIs or practices equally as important to safety as SCIs.

The rationale for selection of SCIs and practices equally as important to safety as SCIs for application of special requirements should be given in Section 4.2.1 of the SSA. The threshold criteria used in selection of these items and practices should be summarized, along with appropriate references, in Section 4.2.2 of the SSA (see Appendix A). 


\subsubsection{Technical Analysis}

The purpose of Section 4.3 in an SSA (see Appendix A) is to demonstrate that limits, controls, and surveillance requirements established by the SSA will ensure that SCIs will perform necessary safety functions. In general, this is accomplished by analyzing performance characteristics of SCIs to show that safety functions can be provided within performance limits of the items. Technical analysis is necessary on all SCIs which have special requirements established in Section 5 of the SSA.

Technical analysis consists of the following activities: (1) determine the safety functions which the SCI must perform, (2) prescribe the conditions (normal operations and upsets) under which the functions must occur, (3) determine the limiting performance capabilities and capacities of the SCI under the required conditions, (4) select parameters to be controlled and the method by which safety margins will be attained, (5) establish setpoints, limits, controls, and surveillance requirements to ensure that the SCI will perform required safety functions, and (6) quantify the safety margin.

Safety functions which SCIs are required to perform can be determined by examining the TDLMs and event trees for the scenarios-of-interest and by reviewing the rationale provided in Section 4.2 of the SSA for selection of the SCIs. Examples of functional safety requirements are: (1) integrity of containment boundaries for radioactive and hazardous materials, (2) ventilation of enclosed spaces following accidental release or generation of explosive gas, (3) automatic isolation of fuel or reactant supplies following loss of process control, (4) automatic detection and alarm of potentially hazardous conditions, and (5) back-up electrical power for operation of essential components.

The most challenging, credible upset conditions under which SCIs must perform their safety functions are established by determining conditions which might result from the accident scenarios-ofinterest. These are the most severe temperature, pressure, concentration of reactive materials, or any other physical or chemical conditions that would challenge the ability of SCIs to perform desired safety functions. As an example, consider the challenge presented to process containment boundaries by a runaway exothermic reaction. In this case, credit should not be taken for loss of heat to the environment (unless justified by analysis). Instead, all the available reaction energy possible should be directed to overheating the containment boundary so that the highest possible temperature is established as the condition under which the boundary integrity is evaluated. In addition to analysis of accident conditions, technical analysis should demonstrate that SCIs provide required safety functions under normal operations and anticipated transients.

Functional limits of SCIs can be determined from design documents, manufacturer's literature, and operating procedures. Functional limits may involve pressure, temperature, humidity, vibration, reactive or incompatible materials, or any other condition which affects the item's ability to function. It is necessary to understand the performance limits of heat transfer components, pumps, fans, electrical power supplies, and other items which the change may rely upon to satisfy a safety function. 
SSA:

Following are examples of some tuchnical analyses of SCIs which should be included in an

1. Evaluate the suitability of material selected for process containment boundaries considering such topics as material compatibility, corrosion, and strength of materials at normal and upset pressures, temperatures, flow rates, or other conditions which challenge the material.

2. Evaluate the appropriateness of component type and capacity relative to functional safety requirements under normal and upset conditions.

3. Examine failure modes, protective setpoints and interlocks associated with instruments and controls which are relied upon to ensure that SCIs provide the preventive or mitigative finctions necessary to protect the containment or confinement boundaries of hazardous anc radioactive substances.

4. Consider the configuration, arrangement, and layout of structures, systems and components relative to initiation of postulated accidents and performance of accident prevention and mitigation functions.

This is not intended to be a complete or comprehensive list of technical analysis, and additional guidance for evaluating SCIs for performance of safety functions may be found in DOE/OR-901 (ref. 14) and DOE Order 6430.1A, (ref. 16).

Continuing the above example of the runaway exothermic process, if the highest temperature estimated in the containment boundary (austenitic stainless steel process pipes and vessels) for this accident is $1000^{\circ} \mathrm{C}\left(1832^{\circ} \mathrm{F}\right)$, then it is known that the stress at which the material will fail is about 9,000 psi. This value is the tensile strength of 304 stainless steel at $1000^{\circ} \mathrm{C}$ from a handbook of properties of materials. If the accident analysis also predicts a simultaneous increase in pressure which produces containment boundary stresses approaching $9,000 \mathrm{psi}$, then controls must be provided to prevent loss-of-containment. Analysis must demonstrate that settings for actuation of pressure relief and temperature control devices will prevent the combination of pressure and temperature which would cause failure of the containment boundary. For example, to control temperature, a Safety Limit (SL) should be set for the process temperature at less than $1000^{\circ} \mathrm{C}$ and a Limiting Contrcil Setting (LCS) should be established at a temperature less than the SL. Similar limits should be established for pressure control. Tecinical analysis should show that the selection of the SL and LCS provide margin for transients, time for automatic or manual response and instrumentation drift and calibration errors. The selection of LCSs at specific values of pressure, temperature, or flow rate should be consistent with consensus industry design standards for the material and conditions involved in the postulated scenario.

As a result of establishing limits and controls as just described and having knowledge of the performance limits for SCIs, it may be possible tc quantitatively describe the associated safety margin. Such calculated margins may be unrealistically lower than reality because of simplifying, conservative assumptions made in the analysis. Judgement is advised in consideration of the degree to which such margins may understate reality and the expense which might be incurred to refine analytical methods to more accurately reflect reality. Although desired in an SSA, determination of the safety margin may be impractical. 
Contents of Section 4.3 of an SSA should document the analysis just described and thereby provide a basis for the special requirements established for SCIs. Assumptions, methods and conditions used in the technical analysis should be recorded. Text should describe how the analytical approach produces pessimistic results. A summary should be given of the functional safety requirements which SCIs must perform. The conditions under which performance must be assured should be stated. Reference may be made to analyses documented elsewhere to avoid placing tedious details in the SSA, but results should be clearly stated and traceable to special requirements stated in Section 5.

\subsection{Requirements}

Requirement, consist of limits, controls and surveillance activities which describe an envelope of parameters and conditions which are selected to ensure safe operation of a facility when proposed changes are implemented. Requirements associated with changes to a facility are established on the basis of assumptions, parameters, conditions, and results from event analysis and technical analysis described in previous sections.

Section 5 of an SSA should document requirements associated with resolution of an as-found condition or a planned change to an existing facility. The requirements should be useful in establishing TSRs in accordance with DOE Order 5480.22 (ref.17) and DOE/OR-901 (ref. 14). Accordingly, information should address Safety Limits (SLs), Operating Limits, Surveillance Requirements and Design Features for Safety (DFS). CSET recommends that the format of Section 5 be based either on systems which are important to safety or significant hazards as opposed to a hierarchial listing of SLs, Operating Limits and DFS; see DOE/OR-901 (ref. 14, section 13.2).

\subsubsection{Safety Limits}

Event and technical analyses recorded in previous sections for active systems and components classified as SCIs should be examined to identify those measurable parameters which can be controlled automatically or by operator intervention to prevent or mitigate postulated accidents. Examples of such measurable parameters include process temperature, pressure and flow rate. SLs should be established for those SCIs having measurable parameters which can be effectively controlled to provide accident prevention or mitigation.

\subsubsection{Operating Limits}

Operating Limits consist of Limiting Control Settings (LCSs) and Limiting Conditions for Operation (LCO).

An LCS is a precise specification of a parameter which is to be controlled. It should consist of the limiting setting in measurable units of the device designed to control the parameter. The primary function of an LCS is to prevent exceeding an SL. Each SL should have at least one LCS. Specific settings are to be selected with allowance for inherent system response times and instrument uncertainties. 
An LCO is the minimum acceptable condition which must exist to initiate or continue operations. LCOs should describe the lowest acceptable functional or performance level for SCIs identified for a change in Section 4 of an SSA.

For those SCIs and practices equally as important to safety as SCIs which do not involve measurable parameters, event and technical analyses should be reviewed to identify minimum conditions to start or continue safety functions. Examples of such conditions include minimum number of redundant systems or components, minimum capacity, minimum confinement or containment, availability of emergency functions (such as power and fire protection), and minimum availability of monitoring devices. For such SCIs and practices equally as important to safety as SCIs, LCOs should be established to ensure the prevention or mitigation of accidents.

\subsubsection{Surveillance Requirements}

Surveillance Requirements relate to test, calibration, or inspection activities which are intended to ensure that the necessary quality of systems important to safety is maintained, that facility operation will be controlled within the SLs, and that LCSs and LCOs will not be exceeded. Surveillance Requirements should be established for SCIs and practices equally as important to safety as SCIs which have SLs, LCSs, or LCOs as described in preceding paragraphs.

\subsubsection{Design Features for Safety}

The DFS are items which provide a safety related function in a passive manner. Examples of DFSs are physical confinement barriers, arrangement and layout of equipment, and materials of construction. DFS may be important in maintaining adequate criticality control, shielding from ionizing radiation, or containment of radioactive or other hazardous materials. The purpose of documenting the DFS associated with a change is to preserve safety margins and the capability of SCIs to perform safety related functions when subsequent changes are made to the facility. Section 5 of the SSA should describe any new DFS or revisions to existing DFS as a result of the change being analyzed. The description should explain why the feature is important to safety so that analysis of future changes might be focused on potential impacts on these features.

\subsubsection{Configuration Management}

Specific existing documents should be identified in Section 5 of an SSA for revision in a controlled manner following approval of the change to the facility. Requirements for configuration management should comply with CSET-8 (ref. 19) and with Standard ESS-CM-101 (ref. 20). 


\section{REFERENCES:}

1. "Safety Analysis and Review System," ESS-FS-201, Revision 0, Martin Marietta Energy Systems, Inc., December 20, 1991.

2. "Environmental Protection Program," ESS-EP-101, Martin Marietta Energy Systems, Inc., February 1992.

3. "Standard for Conduct of Operations," ESS-OP-1, Martin Marietta Energy Systems, Inc., March 1991.

4. "Unreviewed Safety Questions," DOE Order 5480.21, December 24, 1991.

5. "SARUP Unreviewed Safety Question Determination Application Guide," ES/CSET-9, September 1991.

6. "Safety Analysis Report Update Program, Overview and Phase I Implementation," ES/CSET-1/R2, August 1991.

7. "SARUP Safety Assessment Application Guide," ES/CSET-13, January 1992.

8. "SARUP Safety Analysis Report Methodology for Non-Reactor Facilitics," ES/CSET-12, December 1991.

9. "Safety Study Application Guide," ES/CSET-18, to be issued.

10. "SARUP Facility Safety Evaluation Application Guide," CSET-10, July 1991.

11. "Nuclear Safety Analysis Reports," DOE Order 5480.23, April 10, 1992.

12. "SARUP Hazards Screening Application Guide," ES/CSET-2/R1, June 1992.

13. "SARUP Logic Model Application Guide," ES/CSET-3/R1, July 1992.

14. "Guidance for Preparation of Safety Analysis Reports," DOE/OR-901, Revision 2, November 1992.

15. "Occupational Safety and Health Standards for General Industry," 29 CFR 1910, Occupational Safety and Health Administration, U. S. Department of Labor.

16. "General Design Criteria," DOE Order 6430.1A, April 6, 1989.

17. "Technical Safety Requirements," DOE Order 5480.22, February 25, 1992

18. "Safety Classification and Special Design Criteria Development," ES/CSET-15, August 1992.

19. "Supplemental Configuration Management Guidance," CSET-8, June 1991.

20. "Configuration Management," ESS-CM-101, December 28, 1992. 
Appendix A

CONTENTS OF AN SSA

1 Introduction

2 Summary Safety Analysis

3 Description of Facility and Change

4 Analysis

4.1 Event Analysis

4.1.1 Methodology

4.1.2 Hazard Identification

4.1.3 Scenario Development

4.1.4 Quantification of Consequences and Frequencies

4.1.5 Hazard Classification

4.2 Selection of Special Controls

4.2.1 Identification of Safety Class Items

4.2.2 Threshold Consequence Criteria

4.3 Technical Analysis

5 Requirements 


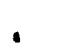

. 


\section{INTERNAL DISTRIBUTION}

T. A. Angelelli

H. L. Arnold, Jr. (10)

J. E. Beavers

M. I.. Benton

D. J. Bostock

K. L. Brady

K. P. Brooks, PORTS

W. A. Burnett, PGDP

D. D. Cannon

W. K. Crowley (50)

F. E. Denny

R. G. Donnelly, PORTS

C. E. Gamm, PORTS

G. G. Fee

G. F. Flanagan

G. F. Hagan

L. E. Hall

S. C. Harris

M. A. Harrison

J. A. Hoffmeister

J. J. Hummer

M. L. Jones

R. A. Just

M. W. Kohring (50)

P. D. Lassiter, PGDP (10)

D. L. Mason

R. S. McKeehan
R. Merriman

M. K. Morrow

F. R. Mynatt

F. S. Patton

H. B. Piper

S. A. Polston, PGDP

J. S. Rayside (10)

D. E. Reichle

D. G. Renfro

M. W. Rosenthal

R. D. Sabin

D. W. Sheffey

K. W. Sommerfeld

W. C. Stoddard

A. W. Trivelpiece

R. D. Wall

E. R. Wagner, PORTS (10)

C. C. Watson (50)

S. R. Wilson

A. K. Zava (70)

Applied Technology Library

Central Research Library

Y-12 Technical Library

Patent Section

Laboratory Records Department (2)

Laboratory Records - RC

\section{EXTERNAL DISTRIBUTION}

J. D. Jackson, SAR Working Group, DOE Field Office, Oak Ridge, TN (5)

J. D. Rothrock, Director, Safety and Health Division, DOE Field Office, Oak Ridge, TN (5) Assistant Manager, Energy Research and Development, DOE Field Office, Oak Ridge, TN Office of Scientific and Technical Information, U.S. DOE, P. O. Box 62, Oak Ridge, TN 37831 (2) 

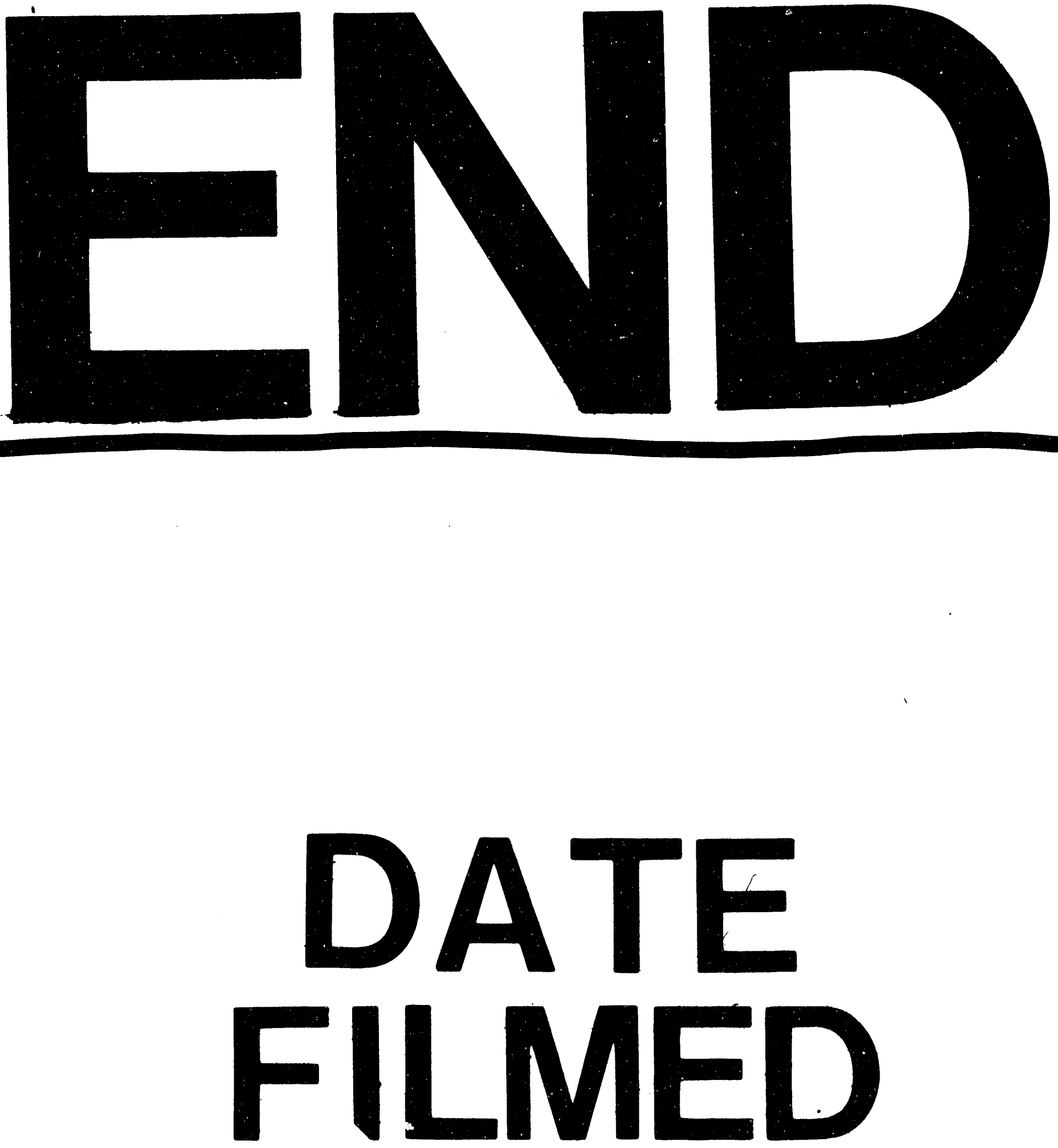

9

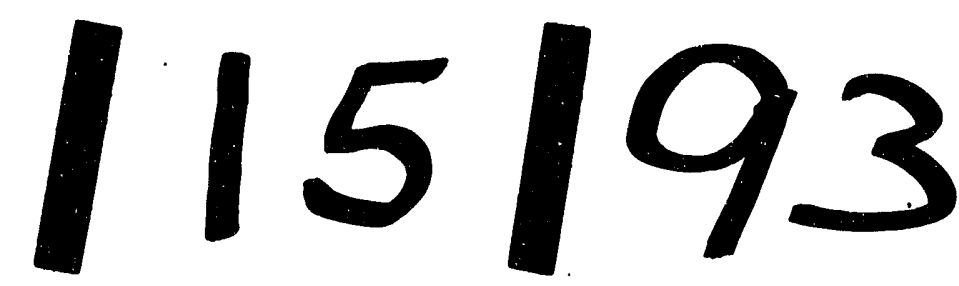


